References

1 Gracey M, Burke V, Robinson J. Aeromonas associated gastroenteritis. Lancet 1982;ii:1034-6.

2 Overman TL, D'Amato RE, Tomfohrde KM. Incidence of "oxidase variable" strains of Aeromonas hydrophila. J Clin Microbiol 1979;9:244-7.

3 Rogol M, Sechter I, Grinberg L, Gerichter Ch B. Pril-xyloseampicillin agar, a new selective medium for the isolation of Aeromonas hydrophila. J Med Microbial 1979;12:229-31.

4 Shread P, Donovan TJ, Lee JV. A survey of the incidence of Aeromonas in human faeces. Society of General Microbiology Quarterly 1981;8:184.

5 Millership SE, Chattopadhyay B. Methods for the isolation of Aeromonas hydrophila and Plesiomonas shigelloides from faeces. J Hyg Camb 1984;92:145-52.

6 Lee JV, Donovan TJ. Isolation and identification of the Vibrionaceae. In: Collins CH, Skinner SS, eds. Detection and isolation of microbes of medical and veterinary importance. London: Academic Press, 1985.

7 Millership SE, Curnow SR, Chattopadhyay B. Faecal carriage rate of Aeromonas hydrophila. J Clin Pathol 1983;36:920-3.

8 Millership SE, Barer MR, Tabaqchali S. Toxin production by Aeromonas spp from different sources. J Med Microbiol 1986;22:311-4.

Requests for reprints to: Dr EH Price, Queen Elizabeth Hospital for Children, Hackney Road, London E2 8PS, England.

\section{Rapid and reliable routine diagnosis of rotavirus using a commercial monoclonal antibody based immunoassay}

D WESTMORELAND, C R ASHLEY, E O CAUL From the Joint District and Regional Virus Laboratory, Public Health Laboratory, Kingsdown, Bristol

Traditionally, electron microscopy has been used for the detection of faecal viruses associated with gastroenteritis because it is the only "catch all" technique available. As rotaviruses are the most important and common cause of acute gastroenteritis in young children $^{12}$ new assays have been developed for their detection. These assays allow a rapid throughput of large numbers of samples-more suitable for the busy diagnostic laboratory and for third world countries which do not have expensive electron microscopy units. There are a variety of assays currently commercially available including radioimmunoassay, latex agglutination, and solid phase enzyme linked immunoassay systems. ${ }^{3-7}$ These assays are supplemented by rotavirus RNA electrophoretic analysis ${ }^{8}$ which also provides invaluable epidemiological data but is too cumbersome for routine diagnostic use.

We describe here the use of a new rotavirus monoclonal based solid phase enzyme linked immunoassay (ELISA) produced by Cambridge Bioscience, Massachusetts, United States of America, and marketed by Boots Celltech Diagnostics Ltd, United Kingdom. We examined stool specimens from all patients up to 7 years of age with symptoms of diarrhoea or gastro-

Accepted for publication 9 June 1987 enteritis from hospitals and general practitioners in Avon over three months during the winter.

Results obtained using this rotavirus (ELISA) were compared with those for an electron microscopy to evaluate both the specificity and sensitivity of the test. Specimens containing other identified pathogens (bacterial, viral, and parasitic) were also tested by ELISA to establish test specificity. In view of previous reports of false positive results obtained using other enzyme linked immunoassays for rotavirus in stool specimens from neonates ${ }^{9}$ results obtained from children less than 2 months old were of particular inter est.

We also present our conclusions regarding sime plicity of the test system and comment on its potentia: usefulness in the diagnosis of sporadic cases as well as outbreaks of rotavirus gastroenteritis.

\section{Material and methods}

Two hundred and sixty three faecal specimens from children less than 7 years of age were tested. These specimens had been submitted by local paediatric units and health centres from children presenting with acute gastrointestinal symptoms during December 1986 to February 1987. Specimens were examined by electron microscopy after concentration by ammonium sulphate precipitation ${ }^{10}$ and by the rotavirus ELISA (Boots Celltech Ltd). All tests were carried out without reference to previous results.

The ELISA was carried out in accordance with the manufacturer's instructions. It is an antigen capture test provided as a complete kit containing four strips of 12 wells coated with antirotavirus monoclonal antibody, enzyme conjugated monoclonal antibody, substrate/chromogen solution and all necessary controls and diluents. About $10 \%$ of faecal emulsions were made in dilution buffer in separate plastic tubes. About $100 \mu \mathrm{l}$ of each sample was transferred to a single well of the test plate with the disposable pipette 
provided. One hundred $\mu \mathrm{l}$ of enzyme conjugated monoclonal antibody was immediately introduced to each well and allowed to incubate at room temperature for one hour in a moist chamber. Wells were washed with five changes of deionised water. After 10 minutes of incubation with the substrate/chromagen mixture the results were visually recorded, a positive result being indicated by an obvious blue colour in the test well. Acid stopping solution was then added to every well and the absorbence of each determined spectrophotometrically.

The sensitivity of the ELISA was compared with that of electron microscopy by preparing 10 -fold dilutions of clarified faecal emulsions in basic Earle's medium, aliquots of which were tested by both techniques.

\section{Results}

The Rotavirus ELISA was simple to use. Visually determined positive results (blue) were distinct from negative wells (colourless). Spectrophotometric measurement of absorbance at $45.0 \mathrm{~nm}$ (A450) after addition of acid stopping solution using the manufacturer's cut off value of $0 \cdot 1$, produced results concordant with visual determination.

The table shows the results obtained from 263 sequential faecal specimens sent to the laboratory. About $22 \%$ of paediatric inpatients with diarrhoea and $10 \%$ of those consulting their general practitioner had demonstrable rotavirus antigen in their stool. Two of 21 specimens from neonates (less than 2 months old) were positive for rotavirus antigen by the ELISA, confirmed by electron microscopy.

All samples which were positive for rotavirus by electron microscopy were confirmed by the rotavirus ELISA. Three specimens which were positive by ELISA were not confirmed by electron microscopy. These were all weak positive results by ELISA when judged visually and by spectrophotometric measurement (A450 of $0.121,0.197$, and 0.225 , respectively). The bulk of positive specimens gave absorbance readings greater than $1 \cdot 5$. Five further specimens gave readings between the manufacturer's recommended cut off value $(0 \cdot 10)$ and $1 \cdot 5$, the maximum value measurable by spectrophotometer. The figure shows results obtained from 10 -fold dilutions

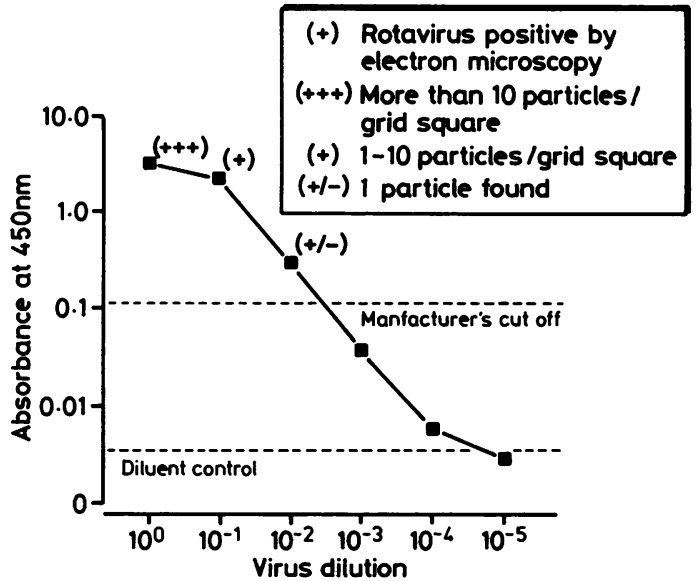

Comparison of serially diluted rotavirus by ELISA and electron microscopy.

of a faecal specimen for rotavirus examined by ELISA and electron microscopy. There is good correlation between the detection of rotavirus by electron microscopy and the intensity of colour produced in the ELISA.

No false positive results were detected in faecal samples containing Strophylococcus enteriditis, $S$ typhimurium, $S$ bellvue, Shigella sonnei, Campylobacter jejuni, Giardia lamblia, or Cryptosporidium. One of 12 samples containing only adenovirus (shown by electron microscopy) produced a weak positive result by ELISA (A450 0 197). Other faecal samples containing astrovirus and small round structured viruses (Norwalk-like) were negative by this assay.

\section{Discussion}

The ELISA rotavirus test examined in this study was easy to use and was both sensitive and specific. The relatively small number of neonatal specimens examined did not produce false positive results in contrast to those of previous reports. ${ }^{9}$ Examination of the titration curve produced from 10-fold dilutions of a positive faecal specimen suggests that this assay will detect antigen below the manufacturer's cut off value. This is supported by the reproducibility of the mea-

Table Results of rotavirus ELISA assay of faeces from children in Avon during the winter of 1986-87

\begin{tabular}{|c|c|c|c|c|c|}
\hline & $\begin{array}{l}\text { No of specimens } \\
\text { tested }\end{array}$ & $\begin{array}{l}\text { No positive by } \\
\text { rota } E L I S A\end{array}$ & $\begin{array}{l}\text { Per cent } \\
\text { positive }\end{array}$ & $\begin{array}{l}\text { Confirmed by } \\
\text { electron microscopy }\end{array}$ & $\begin{array}{l}\text { Per cent confirmed } \\
\text { by electron microscopy }\end{array}$ \\
\hline $\begin{array}{l}\text { In patients } \\
\text { Outpatients } \\
\text { Total }\end{array}$ & $\begin{array}{l}118^{*} \\
145 \\
263\end{array}$ & $\begin{array}{l}26 \\
14 \\
40\end{array}$ & $\begin{array}{l}22 \\
9 \cdot 7 \\
15\end{array}$ & $\begin{array}{l}23 \\
14 \\
37\end{array}$ & $\begin{array}{r}88 \\
100 \\
92\end{array}$ \\
\hline
\end{tabular}

*21 specimens from neonates (less than 2 months old). 
sured A450 of negative specimens, which in this study was never above $0 \cdot 005,1 / 20$ of the manufacturer's cut off value, and invariably gave no colour as determined visually. This suggests that the cut off value has been set too high, but further work is needed to confirm these observations. All but eight positive specimens produced a clear deep blue colour in the wells which gave A450 readings greater than 1.5, when measured spectrophotometrically.

In view of the generally consistent results obtained by electron microscopy and ELISA and the clear resolution of positive and negative specimens in practice we are confident that those few specimens which were weakly reactive in the ELISA and unconfirmed by electron microscopy did, indeed, have rotavirus antigen present. The single specimen which had weak rotavirus reactivity but only adenovirus demonstrable by electron microscopy probably contained both pathogens. Further studies are indicated to confirm these observations.

This ELISA test is fairly rapid, taking about one and a half hours for completion and is marketed in a form which simplifies the execution of small numbers of tests, or larger batches in the event of this being necessary. The test is reliable: incubation times were not found to be critical, in particular, prolonged delay in adding stopping solution did not produce any false positive results. Attempts to abuse the test system by introducing faeces directly into the test wells gave results identical with those obtained from previously prepared faecal emulsions. The use of the manufacturer's diluent was not critical, nor was the amount of faecal material added. Spectrophotometric determination was also not necessary for routine diagnosis, where visual determinations make the test eminently suitable for laboratories where capital equipment is at a premium. In our experience this rotavirus ELISA is the best assay available to date in terms of its versatility, simplicity, sensitivity and specificity. This makes it a good alternative to electron microscopy for those laboratories which do not have this latter facility. Electron microscopy will remain important for the forseeable future as it provides the only "catch all" system currently available. In addition, as new assays are developed for other enteric viral infections, the need to monitor their performance using electron microscopy as the gold standard will increase.

\section{References}

1 Pickering LK. Rotavirus infection. Paediatr Infect Dis 1985; 4:52-6.

2 Flores J, Nakagomi O. Nakagomi T, et al. The role of rotavirus in pediatric diarrhea. Paediatr Infect Dis 1986;5:53-62.

3 Yolken RH, Miotti P. Viscidi R. Immunoassays for the diagnosis and study of viral gastroenteritis. Paediatr Infect Dis 1986:5:46-52.

4 Beardes GM. Bryden AS. Evaluation of a new enzyme-linked immunosorbent assay for rotavirus antigen in faeces. $J$ ('lin Pathol 1981:34:1388-91

5 Cukor G, Perron DM. Hudson R. Blacklow NR. Detection of rotavirus in human stools by using monoclonal antibody. J Clin Microbiol 1984:19:888-92.

6 Yolken RH, Leister FJ. Evaluation of enzyme immunoassays for the detection of human rotavirus. $J$ Infect Dis 1981;144:379.

7 Herrmann JE, Blacklow NR. Perron DM, et al. Enzyme immunoassay with monoclonal antibodies for the detection of rotavirus in stool specimens. $J$ Infect Dis 1985;152:830-2.

8 Herring AJ, Inglis NF, Ojeh CK. Snodgrass DR. Menzies JD Rapid diagnosis of rotavirus infection by direct detection of viral nucleic acid in silver stained polyacrylamide gels. $J$ (ling Microbiol 1982:16:473-7.

9 Krause PJ, Hyams JS, Middleton PJ. Herson VC. Flores Jẹ Unreliability of Rotazyme ELISA test in neonates. $J$ Pediatric $:$ 1983;103:259-62.

10 Caul EO, Ashley CR, Egglestone SI. An improved method for the routine identification of faecal viruses using ammonium sulphate precipitation. FEMS Microbiology Letters 1978:4:1-4

Requests for reprints to: Dr EO Caul, Public Health Laboratory, Myrtle Road, Kingsdown, Bristol BS2 8EL, England.

\section{Letters to the Editor}

\section{Fatal infection in neonates caused by $\boldsymbol{S}$ milleri}

With reference to recent papers by Cox $e t$ $a l^{1}$ and Macgowan and Terry ${ }^{2}$ documenting fatal infection in neonates due to Streptococcus milleri, we report a case of $S$ milleri colonisation in a premature neonate. The 32 year old mother delivered normally after spontaneous rupture of membranes seven days previously. The baby girl was five weeks premature, jaundiced, but otherwise healthy. At delivery a routine infection screen was performed on the baby and a high vaginal swab was taken from the mother. A non-haemolytic streptococcus was isolated after overnight incubation on $5 \%$ horse blood agar from the baby's right and left eyes, nose, throat, right and left ears and umbilicus, and from the mother's high vaginal swab. The organism was identified using the API 20 Strep system (API System SA. Montalieu Vercieu, France) as $S$ milleri biotype III, profile number 5261551 .

The above mentioned articles suggest a link between cervix abnormalities and ascending infection. Our mother had received laser treatment to her cervix in 1982 following abnormal smears. In 1983, 1984. and 1985 she had laparoscopies performed to investigate primary infertility. In 1986 in vitro fertilisation was successfully performed at The Royal Free Hospital, London, resulting in this pregnancy. In this case colonisation did not result in serious tion and both mother and baby progressing well at the time of writing. GILLIAN 胃K PR

JB A Department of Microbioteg. West Norwich Hosfital, Norwich NR2 तु $X$.

References O

I Cox RA, Chen K, Doykendall AL. Wesbæk $P$. Herson VC. Fatal infection in neonafs of 26 weeks gestation due to Streptocorus milleri: report of two cases. J (lin Pthol 1987;40:190-3.

2 Macgowan AP, Terry PB. Streptococcus eri and second trimester abortion. Jf Pathol 1987:40:292-3. 